\title{
List of Infographics
}

Infographic A The relocation of the Bronze Soldier -75

Infographic B The War of Independence Victory Column — 111

Infographic C The memorial landscape at Maarjamäe - 134

Infographic $D \quad$ The Kissing Students 163

Infographics A, B, C, D The trajectory of cultural reinvention through monuments in Estonia -167 
